\title{
Brief Analysis of the Impact of the COVID-19 Epidemic on China's Food Security in 2020
}

\author{
Hang Zheng ${ }^{1}$ \\ ${ }^{1}$ Doctoral School of Management and Business, Hungarian University of Agriculture and Life Sciences, \\ Gödöllö, Hungry \\ Correspondence: Hang Zheng, Doctoral School of Management and Business, Hungarian University of \\ Agriculture and Life Sciences, 2100 Gödöllö, Páter Károly u. 1, Hungry. E-mail: \\ hangzheng906@foxmail.com
}

Received: January 3, 2022

Accepted: January 23, 2022

Online Published: January 26, 2022

doi:10.20849/abr.v7i1.987

URL: https://doi.org/10.20849/abr.v7i1.987

\begin{abstract}
"Don't panic with grain in hand", grain is not only an important strategic goods related to national security, but also the most basic living guarantee for the people. Food security is the most concerned issue of the Chinese government and the people. Against the background of the continuous spread of the COVID-19, China's food security has been challenged. The analysis found that the epidemic has changed people's food consumption structure; epidemic control policies, agricultural meteorology and pest risks and international The changing situation has certain impacts on food production and supply. However, these impacts are short-lived, localized and limited. Fully understanding these impacts and implementing corresponding countermeasures according to their characteristics will further ensure my country's food security.
\end{abstract}

Keywords: COVID-19, food security, food consumption, food production, food supply

\section{Background Introduction}

Since the 18th National Congress of the Communist Party of China, the CPC Central Committee with President $\mathrm{Xi}$ at the core has made food security the top priority in governing the country, and has established a national food security strategy that focuses on self-sufficiency, fully considers domestic conditions, ensures production capacity, moderate imports, and is supported by science and technology. According to the National Bureau of Statistics data show that in 2020, China's grain production was 669.49 million tons, compared with 2019 an increase of $0.85 \%, 2020$ annual grain output hit a new historical high, and consecutive 8 years up to 630 million tons or more. Among them, the output of the four staple grains is 211.86 million tons of rice, 134.25 million tons of wheat, 260.67 million tons of corn, and 19.6 million tons of soybeans. According to the calculation by the CAMES model system of the Institute of Agricultural Information of the Chinese Academy of Agricultural Sciences, China's grain consumption is increased in 2020. The consumption of the four staple grains is: rice consumption of 216.71 million tons, a year-on-year increase of $2.72 \%$; wheat consumption of 138.38 million tons, a year-on- year increase of $6.86 \%$; corn consumption was 287.99 million tons, a year-on-year increase of $2.06 \%$; Soybean consumption was 117.30 million tons, a year-on-year increase of $14.79 \%$; the total consumption of the four staple grains was 760.38 million tons, a year-on-year increase of $4.09 \%$.

Since COVID-19 epidemic (known as epidemic under) outbreak, as of December 28, 2021, the world's cumulative reported cases of COVID-19 diagnosed over 28057 million cases, worldwide deaths over 5.41 million cases. In this situation, in order to control the rapid spread of the epidemic, governments around the world have introduced strict anti-epidemic measures, and many countries have declared a "state of emergency", restricting travel, closing restaurants, bars, scenic spots, schools and various places of gathering.

Under the correct leadership of the Communist Party and the government, and the active cooperation of the people, China has now entered the fifth stage of epidemic prevention and control (the national epidemic prevention and control has become normalized). This article summarizes and analyzes the domestic ration consumption, feed grain consumption, and problems faced by agricultural production and supply during China's fight against the epidemic in 2020, and puts forward some suggestions for the future development of China's food security. 


\section{The Trend of Ration Consumption Has Risen Sharply in the Short Term, and the Overall Trend Has Dropped Slightly}

China's population accounts for nearly one-fifth of the world's population, and its grain output accounts for about one-quarter of the world's, now in a state of absolute ration security. Calculated according to the CAMES model of the Institute of Agricultural Information, Chinese Academy of Agricultural Sciences. In 2020, China's rice grain ration consumption was 159.39 million tons, a year-on-year decrease of $2.25 \%$; wheat ration consumption was 91.1 million tons, basically the same as the previous year; the consumption of corn rations was 9.55 million tons, a year-on-year increase of $0.95 \%$; soybean ration consumption was 14.35 million tons, a year-on-year increase of $2.79 \%$; the total consumption of rations in 2020 is 274.39 million tons, a decrease of $0.99 \%$ from 2019.

Table 1. 2016-2020 China's consumption of staple food rations

\begin{tabular}{cccccc}
\hline project & 2020 & 2019 & 2018 & 2017 & 2016 \\
\hline Rice (10,000 tons) & 15939 & 16306 & 16270 & 16186 & 16142 \\
\hline Wheat (10,000 tons) & 9110 & 9065 & 8896 & 8799 & 8702 \\
\hline Corn (10,000 tons) & 955 & 946 & 943 & 935 & 869 \\
\hline Soybeans (10,000 tons) & 1435 & 1396 & 1253 & 1204 & 1118 \\
\hline Total (10,000 tons) & 27439 & 27713 & 27362 & 27124 & 26831 \\
\hline
\end{tabular}

Data source: CAMES model of Institute of Agricultural Information, Chinese Academy of Agricultural Sciences

Since the outbreak of the epidemic, due to the closure of catering, hotels and other business places, many enterprises and institutions have delayed the resumption of work, and a large number of schools have postponed the start of school, the demand for collective catering procurement has declined. At the same time, based on the consideration of reducing the frequency of going out and hoarding food for emergencies, there have been sporadic purchases of daily necessities such as rice, noodles, oils, and food that can be stored for a long time (convenience food, frozen food, canned food, etc.) in a short period of time, there are even scenes where the shelves are being snapped up. Although the reserves of food for long-term preservation are limited, the reserves of food for daily needs in various places are relatively abundant (According to the relevant regulations on national food reserves, in large and medium-sized cities and areas where prices are volatile, there must be 10-15 days of emergency food reserves), in the short time the demand of market is adequately supplemented, and the price is generally stable. With the gradual deepening of the epidemic prevention and control work, under the strong guarantee of the national food source scheduling, residents' consumption has returned to rationality, and the overall market has become calm after short-term fluctuations.

Due to the large-scale purchase of food by residents in a short period of time, the food purchase and storage of households has increased significantly, but the consumption varieties are limited by the storage period. There were no significant fluctuations. Under the country's vigorous promotion of healthy diets, residents' awareness of healthy diets has been strengthened, and the consumption of animal products such as meat, eggs, and milk has not increased due to the relatively high price. Soybeans, which also belong to high-quality protein substances, are favored by residents and used to replace animal protein, and the consumption of soybeans has been increased.

\section{The Consumption of Staple Grains for Feeding Has Increased Greatly}

2020, the number of livestock rearing grow larger, according to the National Bureau of Statistics, the total number of livestock raised in 2020 is 815.7 million, an increase of 105.8 million over 2019, with an overall increase of $14.90 \%$, of which a significant increase in the number of livestock as a pig, cattle and sheep, increased by 96.10 million, 4.24 million and 5.83 million respectively, an increase of $30.96 \%, 4.64 \%$ and $1.96 \%$ respectively. The national pig inventory has recovered to $84.63 \%$ of 2012 (the highest in 10 years), the national cattle inventory has reached the highest in 10 years, and the sheep inventory has recovered to $98.33 \%$ of 2015 (the highest in 10 years). 
Table 2. Livestock Feeding 2011-2020

\begin{tabular}{ccccccccccc}
\hline project & 2020 & 2019 & 2018 & 2017 & 2016 & 2015 & $\begin{array}{c}\text { Year } \\
2014\end{array}$ & $\begin{array}{c}\text { year } \\
2013\end{array}$ & 2012 & year 2011 \\
\hline large livestock(10,000) & 10265 & 9877 & 9626 & 9764 & 9560 & 9930 & 9952 & 10009 & 10248 \\
\hline Cattle(10,000) & 9562 & 9138 & 8915 & 9039 & 8834 & 9056 & 9007 & 8986 & 9137 & 9384 \\
\hline Horses (10,000) & 367 & 367 & 347 & 344 & 351 & 398 & 416 & 432 & 465 & 515 \\
\hline Donkeys (10,000) & 232 & 260 & 253 & 268 & 259 & 342 & 384 & 426 & 462 & 485 \\
\hline Mules(10,000) & 62 & 71 & 76 & 81 & 85 & 104 & 117 & 138 & 159 & 171 \\
\hline Camels (10,000) & 41 & 41 & 34 & 32 & 30 & 30 & 28 & 27 & twenty four twenty four \\
\hline Pigs (10,000) & 40650 & 31041 & 42817 & 44159 & 44209 & 45803 & 47160 & 47893 & 48030 & 47075 \\
\hline Sheep(10,000) & 30655 & 30072 & 29714 & 30232 & 29931 & 31174 & 30391 & 28935 & 28513 & 28664 \\
\hline Total (10,000) & 81570 & 70990 & 82156 & 84154 & 83700 & 86907 & 87504 & 86837 & 86791 & 86319 \\
\hline
\end{tabular}

Data source: National Bureau of Statistics

The sufficient livestock feeding market has brought a large amount of demand for staple grains. The total number of feedings increased significantly that year, and the staple grain forage market performed extremely well. The total consumption of the staple grain forage market was 331.53 million tons, a year-on-year increase of $13.06 \%$. Among them, rice consumption was 25.73 million tons, an increase of $74.92 \%$; wheat consumption was 21.45 million tons, an increase of 58.07\%; corn consumption was 185.5 million tons, an increase of $2.77 \%$; soybean consumption was 98.85 million tons, an increase of $17.05 \%$. While the production capacity of live pigs has been restored, the scale of cattle and sheep breeding has continued to expand, and the substitution effect is obvious. Under this background, the demand for feed is strong, which has led to an increase in the consumption of staple grains. As the prices of pork, beef and mutton continued to rise, the demand for poultry products previously affected by the epidemic began to recover, which intensified the growth of the consumption of staple grains for feed. Because corn and soybeans are the main raw materials for feed, and the prices of these two raw materials will remain high in 2020, some breeding companies have reduced the ratio of corn and soybeans in feed, and instead increased the ratio of relatively low-priced rice and wheat, in order to achieve the purpose of reducing costs.

Table 3. Feed consumption of staple grains in China from 2011 to 2020

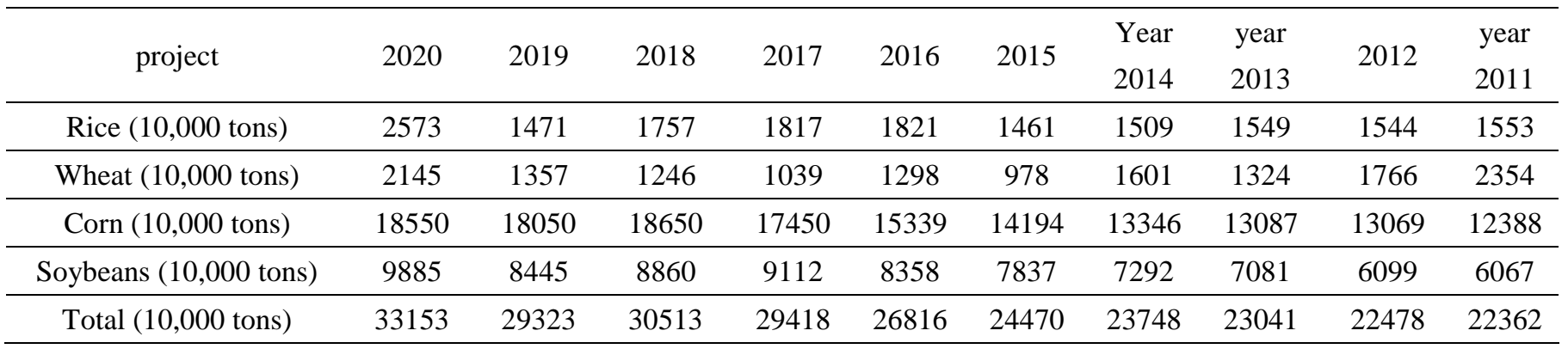

Data source: CAMES model of Institute of Agricultural Information, Chinese Academy of Agricultural Sciences

\section{Problems Faced by Food Production and Supply During the Epidemic}

\subsection{Difficulty in Employment and Rising Labor Costs}

According to the survey data (hereinafter referred to as the survey data) of "The Impact of the COVID-19 Epidemic on the Production of Three Food Crops" by the Institute of Agricultural Economics and Development of the Chinese Academy of Agricultural Sciences, $23 \%$ of the plant industry practitioners believe that they cannot hire workers, and $17 \%$ of the plant industry practitioners believe that labor costs are rising. According to data from the National Bureau of Statistics, the number of migrant workers in 2020 were 285.6 million, a year-on-year decrease of $1.78 \%$. Among them, the number of local migrant workers were $116.01 \mathrm{million}$, a 
year-on-year decrease of $0.44 \%$, and the number of migrant workers were 165.96 million, a year-on-year decrease of $2.67 \%$. The number of inter-provincial migrant workers were 70.52 million, a year-on-year decrease of $6.07 \%$. In the context of epidemic control, the flow of migrant workers has been strictly controlled, and the willingness of migrant workers to go out has also dropped to a low point. The number of migrant workers in areas with severe epidemics has decreased, while small and medium-sized agricultural enterprises with low scale and low degree of modernization lack sufficient manpower, and its production suffers. At the same time, the epidemic control policy requires enterprises to implement a separate meal and wear masks at work, which has caused the labor cost of enterprises to rise sharply.

\subsection{Prices of Agricultural Production Materials Increased Slightly, and Its Supply Was Sluggish}

According to the survey data, $47 \%$ of plant industry practitioners believe that there are transportation and supply problems that cannot arrive in time when purchasing production materials such as seeds, pesticides, and fertilizers. In 2020, the price index of agricultural means of production (the previous year as the base period) was 106.1, of which the price index for feed was 104.2, and the price index for young livestock, young poultry and product livestock was 156.6. At the beginning of 2020, when the epidemic situation was more serious in various places, the prices of agricultural production materials increased greatly in the short term due to the delay in the start of construction, production stoppage, and insufficient distribution of raw materials and packaging by various agricultural enterprises. At the same time, traffic restrictions also prevented the smooth transportation of agricultural production materials, which affected the spring ploughing in the South China and the Southwest China, and delayed the planting of early paddy by about 10 days.

\subsection{Growing Risk of Natural Disasters Threatens Food Production}

In 2020, the affected area of crops in China is 19,960 thousand hectares, a year-on-year increase of 3.63\%, and the disaster- affected area is 7,990 thousand hectares, a year-on-year increase of $1.01 \%$. In some areas of China, the agricultural infrastructure is weak, it is difficult to withstand extreme weather, and it is difficult to guarantee the output. At the same time, a severe locust plague occurred in neighboring Pakistan, and about $40 \%$ of the country's crops were lost; India also experienced a very serious locust plague, which was attacked by about 400 billion locusts. Fortunately, the locust plague did not enter China. Once the locust plague invades, my country's food production will be seriously threatened.

\subsection{Difficulty in Grain Circulation and Unbalanced Industrial Distribution}

Important grain transportation ports such as ports and railways in the main sales area lack transit equipment. Most of China's grain storage equipment is concentrated in the production area, and the sales area lacks grain storage equipment. When the market fluctuates abnormally or faces emergencies, it will affect the state's regulation of the grain market. For example, Henan centrally stores $10 \%$ of China's grain, while Guangdong, the largest consumer province in the country, only has $3 \%$ of the storage capacity. "Transportation of grains from the north to the south" leads to long transportation distances and insufficient railway transportation capacity, which is only $5 \%$ at the highest.

\subsection{The International Environment Is More Complex and Volatile, Affecting Domestic Food Production and Prices}

Since the outbreak of the epidemic, despite WHO Director-General Tedros Adhanom Ghebreyesus calling for "no reason to take unnecessary measures to interfere with international travel and trade", many countries have still imposed food export restrictions: Vietnam, the world's third largest rice exporter, has banned rice exports. Kazakhstan, one of the largest wheat exporters, banned the export of wheat, Egypt banned the export of beans, Serbia stopped the export of sunflower oil, and other countries have issued corresponding grain export restrictions. The international wheat price is lower than the domestic price. In 2020, China's wheat imports were 8.38 million tons, a year-on-year increase of $140.1 \%$; China's corn imports in 2020 were 11.30 million tons, a year-on-year increase of 135.7\%; China's soybean imports in 2020 were 100.32 million tons, a year-on-year increase of $13.3 \%$. China's grain self-sufficiency rate has always been around $95 \%$, and rations are absolutely safe. Imported grains are mostly based on structural adjustment and the consideration of meeting the individual needs of residents. International grain prices and export restrictions mainly affect China's processing and feed grain production and prices.

\section{Countermeasures and Suggestions}

At present, my country's food production is sufficient to meet the consumption needs of residents. However, in the context of the epidemic, it is mainly exposed that traffic control has a great impact on logistics and transportation, the industrial layout of production and sales regions is inappropriate, market supervision is 
insufficient, risk management and control awareness is insufficient, and food safety communication mechanism. Unsound set of problems. In view of these deficiencies and deficiencies, the following countermeasures and suggestions are put forward to further ensure my China's food security:

\subsection{Adjust the Industrial Layout of Production and Sales Regions, and Increase Investment in Infrastructure} Related to Grain Transportation

Increase support for processing enterprises in major grain producing areas, and strive to reduce intermediate links in grain disposal, so as to stabilize grain supply. Adjust the part of the grain industry in the main sales area to ensure that the area has a certain self-sufficiency. At the same time, considering the large population distribution, developed economy and large demand for grain in the main sales area, an additional grain storage institution should be established in this area to facilitate the supply security in the event of emergencies. In addition, increase investment in infrastructure related to grain transportation, strengthen the construction of railways and waterways with large carrying capacity, safe transportation, and high transportation efficiency, repair related foundations, organize professional handling teams, and focus on improving the operation level.

\subsection{Make Full Use of E-commerce and Express Logistics to Protect Food Supply}

Throughout the period of the epidemic, people's dependence on e-commerce platforms for consumption has risen sharply. E-commerce and express logistics have provided key logistics guarantees, fully satisfying food supply and market demand, and also alleviated and weakened the panic in the market from the side. "No-contact" services provided by e-commerce and express logistics avoid close contact between people and weaken the transmission route of the COVID-9 virus. With the help of e-commerce, trade digitization can also be realized, which can not only improve market supervision and reduce management costs, but also realize multi-platform and multi-channel connectivity through online, creating a larger market and more opportunities for food trade.

\subsection{Strengthen Market Supervision and Ensure Information Openness and Transparency}

Market supervision should start with product traceability. After the outbreak in Xinfadi, Beijing, although the root cause of the epidemic was quickly identified through technical means, it was traced back to the source after all, and could not be controlled from the source at the beginning. A product traceability mechanism should be established to control all aspects of product information from production to circulation, so as to enhance the intensity of market supervision. In addition, the openness and transparency of market information will help to avoid the generation of panic among the people, so that farmers can reasonably arrange the production order according to the information.

\subsection{Strengthen the Awareness of Risk Management and Control, and Establish an Emergency Response Plan} Mechanism for Public Emergencies

Strengthening risk management mainly includes two aspects. One is to establish and improve the data monitoring system of the entire grain industry chain, to collect and analyze data in terms of production, consumption, inventory, supply, trade, price, and cost, and to control the dynamics of the entire industry chain in real time. The second is the early warning, information release and technical guidance of natural disasters and pests and diseases, especially in the overall unfavorable environment of the overall deviation of agricultural meteorology in 2020 and the superposition of traditional pests and diseases and imported pests. In addition, according to different circumstances, the emergency response plan should be negotiated with each department and each link in advance, so that when a public emergency occurs, there will be no unprepared battle. At that time, each department and each link will perform their duties to properly respond the impact of sudden public events.

\subsection{Improve the Food Risk Communication Mechanism to Win the Trust of the Public}

During the epidemic, although China's food supply was orderly and fully satisfied the people's demand for food, it did not mean that China's food security was perfect. With the enhancement of people's health awareness and the premise that the media dominates public opinion, a single food safety incident is likely to be magnified and evolve into a social food safety crisis. At present, the Chinese government departments have not yet formed a unified supervision mechanism. The Food Safety Committee is a temporary agency that only convenes various departments to form a community to deal with it when needed. Secondly, although China has a variety of social platforms for enterprises, people, and experts to communicate with each other, it lacks a public platform that integrates positive communication between enterprises, people, experts, and government agencies. Companies want to communicate with people, or people want to communicate with companies. Communication can only be carried out through Weibo, WeChat, QQ and other platforms. Therefore, it is very important to establish a public food risk communication platform where the government can publish policies, companies can publish news, and 
the public can speak. In addition, in the event of food safety incidents, enterprises are not very motivated to actively communicate and are often passive. The state should guide enterprises to take the initiative to communicate and release information to the public to gain public trust and minimize risks, rather than trying to hide. Finally, the media often report problems in an exaggerated form in order to gain attention and increase viewership. The government should issue relevant policies and regulations to restrict the behavior of the media, ensure that their reports are true, accurate and legal, and stipulate that the media verification should be done before reporting.

\section{References}

Agricultural Development Bank Food Security Strategy Research Group, \& Xiu, J.-Q. (2021). Research on China's Food Security Strategy. Agricultural Development and Finance, (11), 32-37.

Deng, Y.-J., Zhou, X., Often, Y.-Q., Zhu, L.-J., \& Qin, Y.-W. (2022). Dilemma of China's Agricultural Trade Development epidemic period. Business Economics, (1), 3-6, 34.

Lv, J.-B. (2016). Research on food safety risk communication mechanism. Henan University of Technology.

Niu, W.-K. (2020). The impact of the new crown epidemic on China's food safety and countermeasures. Cereals, Oils and Food Science and Technology, 28(5), 64-68.

Song, L.-L., Zhang, L., Tao, Y.-Y., \& Hou, L.-W, (2020). Competitive Selection. Analysis of novel coronavirus pneumonia epidemic on China's food industry. Chinese Agricultural Science and Technology, 22(6), 12-16.

White Paper on "Fighting the New Coronary Pneumonia Epidemic: China's Actions".

White Paper on "Food Security in China".

Yang, H.-Y., \& Guo, Z.-T. (2009). Current Situation and Development of China's Grain Storage Facilities Construction. Grain Science, Technology and Economy, (3), 31-33.

Zheng, M.-L., \& Ji, L.-G. (2010). Problems and Countermeasures of "Transportation of Grain from North to South". Grain and Food Science and Technology, (S1), 21-26.

Zhong, Y., Pu, L.-Z., Liu, M.-Y., Niu, K.-Y., \& Zhang, L. (2020). Analysis of the Impact of the New Coronary Pneumonia Epidemic on China's Food Security and Suggestions for Stabilizing Yield. Issues in Agricultural Economics, (4), 13-22.

\section{Copyrights}

Copyright for this article is retained by the author(s), with first publication rights granted to the journal.

This is an open-access article distributed under the terms and conditions of the Creative Commons Attribution license (http://creativecommons.org/licenses/by/4.0/). 